\title{
MARIA JESÚS RUBIERA, UNA APORTACIÓ A L'ESTUDI DELS ARABISMES DEL CATALÀ I A LA NORMALITZACIÓ LINGÜÍSTICA
}

\author{
Josep FORCADELL SAPORT \\ Universitat d'Alacant
}

\section{Raons que em vam fer aproximar-me a l'arabista Maria Jesús Rubiera}

Entre els valencians hi ha (o hi havia) una simpatia tradicional pel període musulmà de les actuals terres valencianes. És una opinió popular, encara que no sempre exacta o ben documentada, que les construccions antigues, les ruïnes, les xarxes de rec, l'agricultura i, fins $\mathrm{i}$ tot, bona part dels tòpics de la literatura paisatgística de principis del segle XX, als quals era molt fidel V. Blasco Ibáñez, tot era moro o d'aquella època, inclosos els valencians. El coetani himme regional és una mostra representativa d'aquella visió folklòrica i de sarsuela de la realitat.

Però aquesta visió popular, davant de qualsevol reflexió amb un mínim de documentació a la mà, no s'aguantava; calia una visió del passat més sòlida i un coneixement o una interpretació de la realitat que no estigueren distorsionades per tòpics emmascaradors.

En els últims vint-i-cinc anys s'han escrit una sèrie de novel les $\mathbf{i}$ d'obres poètiques en la literatura catalana feta al País Valencià que tracten o estan ambientades en el passat islamic, des d'una perspectiva delerosa de recuperar un passat que ens havia estat amagat, pero amb una major fonamentació cientifica deutora de les aportacions dels estudis universitaris sobre la història del País Valencià. La recuperació d'aquella societat, que forma part del nostre llegat històric, o la creació 
d'un espai per a projectar l'imaginari col-lectiu en una societat passada més o menys iđealitzada, ha sigut i és un referent fructffer per a la creació literària dels valencians. Aquest tema, l'ha estudiat un altre arabista, Mikel de Epalza, que va encunyar el terme de morofilia per a descriure aquest fenomen de la literatura valenciana ${ }^{1}$.

A la curiositat inicial que els valencians podíem sentir per tots els elements més o menys d'època islàmica que pogueren estar presents en la cultura valenciana actual, caldria afegir la repercusió de la lectura d'autors com el lingüista Manuel Sanchis Guarner, l'assagista Joan Fuster o els historiadors Joan Reglà o Enric A. Llobregat, entre altres. La lectura de les seues obres va estimular molts estudiants dels anys setanta i vuitanta a fer una aproximació al passat islàmic amb unes perspectives científiques $i$, a la vegada, profundament respectuoses amb el nostre passat historic i l'aportació d'aquells pre-valencians a la nostra cultura actual.

Per aixo, comptar amb el consell i l'opinio de Maria Jesús Rubiera, i d'altres arabistes del Departament d'Estudis Àrabs i Islàmics de la Universitat d'Alacant, ha sigut $i$ és una fortuna, no sols per als qui estem vinculats amb la Universitat d'Alacant, sinó per a tots els valencians i per a la filologia catalana.

El meu treball diari al Servei Tènic de Normalització Lingüística des de juny de 1986 m'obligava a resoldre dubtes sobre els nombrosos arabismes presents en la documentació medieval i d'època moderna que ens arribaven al Servei, que, d'altra banda, no sempre estaven ben resolts o suficientment documentats pels grans diccionaris disponibles ${ }^{2}$.

${ }^{1}$ Vegeu Míkel de Epalza, "Alguns aspectes de la morofília literària actual al País Valencià", Sharq al-Andalus. Estudios Árabes, 1, ps. 169-172.

2 Recorde, per exemple, algunes d'aquelles consultes en què, després de pegar-li voltes a una paraula, Maria Jesús Rubiera, trobava l'etimologia o identificava una forma no documentada d'un vell arabisme valencià i esclatava d'alegria i de goig per la petita troballa lingüística. Així, per exemple, el dia que, a partir d'una documentació d'Elx dels segles XIV i XV exhumada pel professor Josep Hinojosa que el Servei estava revisant, va llegir uns arabismes, gebels i gilis, amb el significat de terrenys 'dels absents' o 'dels que havien fugit de les seues terres', de la mateixa arrel i significat que algueber, hàpax de la crònica de Jaume I en la conquesta de Mallorca que Coromines no explica de manera satisfactòria, potser per falta de claredat del context o per no disposar de més 
A més a més, hi havia la curiositat per conéixer el considerable cabal dels arabismes encara vius en el català actual.

Al poc de temps de constituir-se el Servei Tècnic de Normalització Lingüística de la mà de Rafael Alemany, els arabistes de la Universita d'Alacant, i especialment, Maria Jesús Rubiera, en aquells moments directora del Departament, ens van demanar la col laboració del Servei en la revisió dels seus textos en català. A banda de la qüestió dels arabismes s'hi plantejava una altra que en aquell moment estava per resoldre d'una manera unitària i definitiva: la transcripció dels mots àrabs al català i les interferències d'altres llengües, especialment el francés, en l'adaptació de termes àrabs al català modern.

Aquestes dues raons, l'oferiment d'una opinio solida per a aproximar-nos al món islàmic, especialment als aspectes lingüístics, i la voluntat decidida de Maria Jesús Rubiera per conéixer i usar la llengua i la literatura pròpies del seu país d'adopció i els contactes amb el nostre Servei que se'n derivaven, van fer que necessitàrem sovint l'orientacio i el consell d'aquesta arabista.

L'opcí de Maria Jesús Rubiera per fer un ús normal del valencià com a llengua de relació i com a llengua d'expressió científica va suposar per a nosaltres una font de treball estimuladora i un repte. Així, a més de continuar en els seus treballs i les reflexions sobre els diferents camps de la filologia i de la literatura relacionades amb el País Valencià i tota la cultura catalana, en un acte de coherència intel-lectual i amb una generositat mereixedora d'encomi va començar a escriure $i$ a parlar en valencià. En aquest procés de recerca cientifica i, alhora, d'aprenentatge de la llengua va comptar amb la col-laboració de diversos membres del Departament de Filologia Catalana i amb el Servei de Normalització Lingürstica.

Per a nosaltres, un Servei que acabava de nàixer $i$ necessitava demostrar la seua utilitat tant en l'àmbit administratiu com en el de suport a l'ús del valencià en tots els àmbits acadèmics, Maria Jesús Rubiera va ser un estímul decisiu. Una catedràtica, ens enviava contínuament materials per a traduir i, ben prompte, per a revisar. Les

exemples. Vegeu Joan Coromines, Diccionari etimològic i complementari de la llengua catalana, I, Curial Edicions Catalanes, Barcelona, 1983 (4a ed.), s.v. algueber. 
dificultats que, de vegades, comportava la traducció, bé per la matèria objecte de reflexio o per aspectes estrictament lingüístics o de transcripció, eren recompensades, en lliurar la versió revisada, amb llargues converses, explicacions i matisacions sobre aspectes culturals, sobre les transferències lingüistiques i culturals o sobre aspectes més estrictament filologics.

En aquest context se'm va despertar la curiositat, i la necessitat, per conéixer el món islàmic i els contactes fructffers entre l'àrab i el català, especialment en les terres valencianes.

Vaig tenir l'oportunitat de seguir un curs d'àrab i un curs de doctorat sobre els arabismes del català impartits per Maria Jesús Rubiera. Aquest curs, al qual van assistir també com a alumnes tots els membres del Departament, va esdevenir un seminari setmanal sobre els arabismes del català al llarg de tres cursos acadèmics i va comptar amb beques del Pla EVA de la Generalitat Valenciana per a la realització de diversos projectes sobre arabismes. La generositat $\mathrm{i}$, molt sovint, la paciència a explicar-me els fets culturals i literaris de l'islam o a repetir-me els fenòmens lingǘrtics de l'àrab i el seu pas a les llengües romàniques, han estat determinants en les relacions entre mestra $\mathbf{i}$ alumne, la qual ha tingut l'amabilitat de considerar-me, en alguna ocasió, com a col-laborador.

\section{La normalització linguíistica. L'ús dels arabismes en el català actual}

En el català modern, i especialment des de la recuperació d'institucions d'autogovern dels diferents territoris de llengua catalana, s'ha produit, i continua produint-se, un moviment d'anada a la documentació històrica per a obtenir arguments que ajuden a fixar la terminologia específica de tots els camps que en els últims anys es poden expressar amb una certa normalitat en català. És cert que l'existència d'un terme històricament no en justifica per si mateix la recuperació i la difusió. La fonamentació històrica pot ser una raó, però convé tenir present, a més, el sistema lingüistic actual $\mathrm{i}$ les evolucions que s'hi han produït; les solucions adoptades per altres llengües de cultura veïnes, i, si cal o n'hi ha, les recomanacions o els acords dels organismes internacionals que directament o indirectament es refereixen a la terminologia. 
Per a fixar els criteris d'aquest procés d'anada i tornada al passat per trobar solucions lingürstiques vàlides per a les necessitats d'avui o per proposar solucions més coherents amb el geni lingüistic del català, són fonamentals les aportacions que es van fer en els cicles de conferències "Tradici 6 i modernitat en el llenguatge administratiu" ${ }^{3}$ i de diversos treballs sobre el llenguatge jurídic i administratiu en epoca foral, a Catalunya, impulsats per Carles Duarte i Montserrat des de l'Escola d'Administració Pública de Catalunya, i, al Pars Valencia, per Emili Casanova des de la Facultat de Filologia, entre altres. Una bona mostra d'aquestes aportacions es poden trobar en la revista Llengua $i$ Dret publicada per l'Escola d'Administració Pública de Catalunya.

En les sessions del seminari sobre arabismes del valencià hem tingut presents bona part d'aquests criteris. D'altra banda, estem convençuts que, més enllà de la simpatia pels arabismes històrics en desús, hi ha la convicció que en els usos cientffics, en els registres especialitzats, i més encarca en l'ús col'loquial, les llengües tenen unes dinàmiques $i$ unes convencions que no són facils d'alterar. Una altra cosa és el registre literari, en el qual es pot fer un esforç de recuperació i de recreació d'arabismes avui en desús o que tenen una vigencia esmorteïda o reduïda a un àmbit geogràfic determinat, o bé que tenen un significat molt restringit. D'això, en tenim bones mostres en la literatura catalana dels últims vint-i-cinc anys de la mà d'autors com Josep Lozano, Ferran Cremades, Miquel Ferrà o Josep Piera, algun dels quals van ser invitats pel Departament a presentar les seues obres a la Universitat d'Alacant.

Pel que fa a l'estudi dels arabismes, es plantegen dos camps de recerca ben diferents. D'una banda, la documentació i la fixació dels arabismes històrics, tant si estan en desús com si encara estan vius, i els processos que han seguit fins arribar a les formes actuals $i$ al seu significat, o significats, en català. D’una altra, hi ha el repte de

3 Carles Duarte i Raimon Alamany (eds.), Tradició $i$ modernitat en el llenguatge administratiu, Escolad'Administració Pública de Catalunya, Barcelona, 1986, amb conferències de C. Duarte, R. Comet, X. Lamuela, A. Santamaria, E. Casanova i M. T. Cabré. L'any 1986 es van fer les II Jornades, que es van publicar amb el títol El llenguatge administratiu: metode $i$ organització, Barcelona, 1988. 
l'adaptació dels nous arabismes que entren ràpidament a través dels mitjans de comunicacio, sovint vehiculats a través d'altres llengües, especialment l'anglés i el francés, o la qüestio, cada dia més present, de l'onomàstica islàmica i la comunicació amb els immigrants del Magrib.

En tots dos camps, hi ha un tema fonamental en el qual convé aprofundir: la unificació dels criteris de transcripció de l'àrab al català. Per provocar la reflexió sobre aquest tema, el Departament d'Estudis Àrabs i Islàmics va convocar unes Jornades Tècniques sobre la Normalització dels Arabismes en Català, que van tenir lloc a la Universitat d'Alacant els dies 27 i 28 d'octubre de 1986, promogudes per Maria Jesús Rubiera ${ }^{4}$. Les conclusions d'aquelles Jornades van ser presentades a l'Institut d'Estudis Catalans, amb altres consideracions de Maria Jesús Rubiera referides als arabismes del català.

L'Institut d'Estudis Catalans, l'any 1990, va publicar en els Documents de la Secció Filologica, I, una "Proposició sobre els sistemes de transliteració i transcripció dels mots àrabs al català" elaborada pel professor de la Universitat de Valencia Lluís B. Polanco a partir dels resultats de les Jornades que havien tingut lloc a la Universitat d'Alacant'. En aquest document, l'Institut d'Estudis Catalans respon, a més, a la consulta de Maria Jesús Rubiera sobre els mots d'origen àrab acabats en $-\ell$, més genuïns en català que no les terminacions en -ita o -ida, en molts casos amb un considerable arrelament però que responen a solucions franceses.

En el procés actual de normalització lingüística del català $i$, de retruc, de normativitzacio d'aquells aspectes encara no ben resolts, com ara alguns relacionats amb l'adaptació dels nous arabismes, la revisió d'alguns arabismes calcats del francés o la fixació i la difusió d'uns criteris de transcripció de l'àrab al català, les aportacions de Maria Jesús Rubiera han sigut decisives, per la seua activitat cientifica, per les

${ }^{4}$ Vegeu les notícies en Llúcia Martín, "Reunió tècnica per la normalització de noms i textos d'origen àrab", Sharq al-Andalus, 4 ps. 377-383, i Lluís B. Polanco, "Sistemes de representació gràfica de mots àrabs en català", Sharq alAndalus, 5, ps. 11-30.

5 Aquest document va aparèixer en Sharq al-Andalus, núm. 5 (1988), amb el títol "Sistemes de representació gràfica de mots àrabs en català", amb una excel·lent introducció sociolingüística i històrica. 
seues publicacions $i$ pels treballs en marxa actualment. Al darrere d'aquest interés s'hi podria trobar la ferma convicció d'una arabista que entén que cal fer la normalització de l'àrab i el català, de l'aportació mútua entre totes dues llengües i totes dues cultures. Sols aixi es podran posar en el seu lloc les relacions recíproques entre la llengua àrab i la catalana al llarg de la història i fer del català una llengua capaç d'adaptar, sense intermediaris, els arabismes que les noves relacions internacionals $i$ els agils mitjans de comunicació ens porten diàriament a casa amb les noticies de tot el món d'expressió àrab. Aixo, entenc, és el que pretén ella, i tot el Departament d'Àrab: d'una banda, estimular la formació d'arabistes catalanoparlants que s'interessen per totes dues filologies i, d'una altra, aportar bona part de la seua activitat científica $i$ academica per al coneixement de les relacions entre ambdues cultures.

\section{Algunes reflexions generades pel mestratge de Maria Jesús Rubiera}

Cada cultura que ha passat per aquestes terres o amb la qual hem tingut o mantenim algun contacte, ha aportat noves tecniques, noves institucions, nous elements i nous materials i, conseqüentment, els noms que els designen. En el llarg procés de conformació del lèxic valencià actual podem trobar una considerable quantitat de mots d'origen àrab o vehiculats per l'àrab (l'algeps o guix totes dues formes provinent del grec gypsós, per exemple).

Quan una tècnica o un element de la cultura ha quedat en desús (ex. l'atovó o atova d'argila o fang assecat al sol; el safareig, etc.), es pot produir un desplaçament semàntic o bé aquest mot tendeix a desaparèixer a poc a poc. El mateix ha ocorregut amb les institucions, els carrecs i els treballadors de l'Administració pública. Uns han desaparegut (el mostassaf, per exemple) o altres han desplaçat el seu significat originari (l'agutzir 'oficial de la justícia o del municipi', que de wazir 'ministre', 'visir', ha passat a designar un humil funcionari municipal que ja ha desaparegut en moltes poblacions).

El nivell de coneixement, de conservació $i$ de (re)utilització del patrimoni cultural i de la llengua que el conforma és un dels testimonis més fidels del grau de cultura d'un país i no hi ha raons per a renunciar-ne a l'ús mentre siguen vàlids. El passat islàmic, especialment el 
llegat lingüístic, de les actuals terres de parla catalana ha de ser valorat i acceptat com un fet més de la història d'aquestes terres i de la conformació del català.

La recuperació d'un terme o l'ús d'un mot en el sentit primigeni o amb les modificacions generades pels desplaçaments semàntics que els canvis temporals i culturals poden produir, és una aportació dels filolegs, en aquest cas dels arabistes, que els usuaris del català i de les altres llengües deutores de l'àrab hem d'agrair $i$ de valorar positivament. L'estudi dels arabismes és, encara, una font de sorpreses capaç d'enriquir la llengua viva i una eina imprescindible per a l'estudi de la documentació d'època foral.

Convé tenir presents les reflexions dels arabistes sobre el llarg i desigual període de contacte entre l'àrab i el català durant quasibé nou segles, no sols pel que fa als fenomens de transmissió cultural i lèxica, sinó també a l'evolució que totes dues llengües, o les varietats geogràfiques o socials que estaven en contacte immediat, van anar experimentant $i$, per tant, les diferents grafies amb què en les llengües receptores, una vegada superat el filtre fonologic, representaven allo que escoltaven als veïns de llengua i cultura diferent, pero no del tot estranya.

Els contactes entre l'àrab i el català al llarg de la història i actualment, és un camp obert que encara té molts buits per emplenar. I, en aquest àmbit, s'ha d'avançar de la mà de lingüistes coneixedors de l'àrab i del català.

En l'estudi dels contactes culturals i lingürstics entre dues societats de civilització i llengües tan diferents com la islàmica i la cristiana en l'epoca foral valenciana -com ja fa temps que reclamava Germà Colón, i predicava amb l'exemple en l'edició dels Furs de Valencia amb Arcadi Garcia ${ }^{6}$ - cada volta es fa més necessària la col laboració de lingüistes i d'historiadors per a entendre rectament la documentació conservada.

Com a ex-alumne i company del seminari d'Arabismes del Català, però sobretot com a lector $i$ usuari dels vostres treballs, m'agradaria que continueu sent generosa i suggeridora de projectes amb tots aquells que s'acosten demanant-vos consell i opinió. Faig meues les paraules del

"Vegeu la interessant i completa "Introducció" de Colón, Germà i García, Arcadi, Furs de València, vol. I, Ed. Barcino, Barcelona, 1970. 
vostre mestre Emilio García Gómez en el pròleg de 1981 al vostre llibre Ibn al-Yayyäb. El otro poeta de la Alhambra ${ }^{7}$, i us desitge que gaudiu molts anys del vostre treball, perque, estic convençut, que l'arabística, la filologia i la cultura catalana, n'eixirem beneficiats.

7 "Sólo me resta expresar mis deseos de que María Jesús Rubiera tenga una larga vida, llena de afán y goce del trabajo que le permita abordar y ampliar sus felices investigaciones en el fecundísimo campo de los estudios nazaríes". Reeditat pel Patronato de la Alhambra i Generalife, Granada, 1994. 